\title{
The role of vaccination in successful independent ageing
}

\author{
J.E. McElhaney ${ }^{\mathrm{a}, *}$, G. Gavazzi $^{\mathrm{b}}{ }^{\text {, J. Flamaing }}{ }^{\mathrm{c}}$, J. Petermans ${ }^{\mathrm{d}}$ \\ ${ }^{a}$ Advanced Medical Research Institute of Canada, 41, Ramsey Lake Road, Sudbury, Ontario, Canada \\ ${ }^{\mathrm{b}}$ University Clinic of Geriatric Medicine, University of Grenoble, 38000 Grenoble, France \\ ${ }^{\mathrm{c}}$ Department of Geriatric Medicine, University Hospitals of Leuven, Department of Clinical E' Experimental Medicine, KU Leuven, Herestraat, 49, 3000, Leuven, \\ Belgium \\ ${ }^{\mathrm{d}}$ CHU Liège, route de Gaillarmont, 600, 4032 Chênée, Liège, Belgium
}

\section{A R T I C L E I N F O}

\section{Article history:}

Received 9 November 2015

Accepted 19 January 2016

Available online 12 February 2016

\section{Keywords:}

Infectious diseases

Vaccine

Vaccination policy

Vaccine uptake rate

\begin{abstract}
A B S T R A C T
Ageing increases the risk and severity of infectious diseases, especially when chronic diseases are present. Healthcare providers generally view vaccination as a childhood intervention and consider vaccination of the elderly not to be sufficiently effective due to immunosenescence. However, the burden of frequent vaccine-preventable diseases, such as influenza, pneumococcal disease and herpes zoster, increases with age, so that the perceived lower vaccine effectiveness should be considered in the context of this higher burden. Vaccination can prevent infection and mortality hospitalization and functional decline, and their consequences thereby having a positive impact. The use of medications will be reduced (e.g. antibiotics, analgesics) and therefore the iatrogenic risk would be lower. This contributes to an improved quality of life and to successful ageing. Many countries recommend influenza and pneumococcal vaccination in the elderly and, more recently, some recommend the live-attenuated herpes zoster vaccine. However, better guidelines and recommendations, especially for frail individuals are needed. Protection may be improved by offering vaccination to younger, fitter individuals, before they become frail. In addition, offering vaccination to caregivers and others who are in contact with the elderly could also improve protection. Many studies have demonstrated that influenza, pneumococcal and herpes zoster vaccinations in the elderly are cost-effective and can even be cost-saving. Healthcare providers and public health decision-makers need to understand more fully the value of vaccination and to consider it as an important preventive tool in the promotion of successful ageing.

() 2016 Elsevier Masson SAS and European Union Geriatric Medicine Society. All rights reserved.
\end{abstract}

\section{Introduction}

Ageing is one of the greatest social and economic challenges of the 21st century. Life expectancy is continuing to increase and many populations are going through major demographic changes resulting in a much older population structure. It is estimated that by 2025 , more than $20 \%$ of Europeans will be aged $\geq 65$ years, with a bigger increase of those aged $\geq 80$ years. Since ill health and disability increases with age, ageing populations place a greater burden on society generally and healthcare systems in particular.

\footnotetext{
Abbreviations: BADL, basic activities of daily living; IADL, instrumental activities of daily living; CMV, cytomegalovirus; HZ, herpes zoster; VZV, varicella zoster virus; PHN, post-herpetic neuralgia; ZBPI, Zoster Brief Pain Inventory; PCV, pneumococcal conjugate vaccine; HCPs, healthcare professionals.

* Corresponding author. Tel.: +1 7055237100 x2725; fax: +1 7055237325 .

E-mail addresses: jmcelhaney@amric.ca (J.E. McElhaney), GGavazzi@chu-grenoble.fr (G. Gavazzi), johan.flamaing@uzleuven.be (J. Flamaing), jean.petermans@chu.ulg.ac.be (J. Petermans).
}

In this paper, we will examine the role of vaccination in a global approach to successful, independent ageing and increased healthylife expectancy.

\section{Higher risk of infectious diseases in the elderly}

Ageing does not affect people's health in the same way, but about $80 \%$ of older people ( $\geq 65$ years old) have at least one underlying chronic disease ('usual ageing'), and 25\% have more than three underlying chronic diseases [1]. While some seniors 'age successfully' and have no underlying chronic diseases, others become frail and can need long-term care in specialised facilities. It is not easy to predict how people will age, but many factors have been reported to contribute, such as chronic diseases, functional status, ageing immune system (immunosenescence), loss of mechanical barrier function and increased risk of exposure in congregated settings, including nursing homes [2]. Poor nutritional status and lack of physical activity can contribute to an increased 


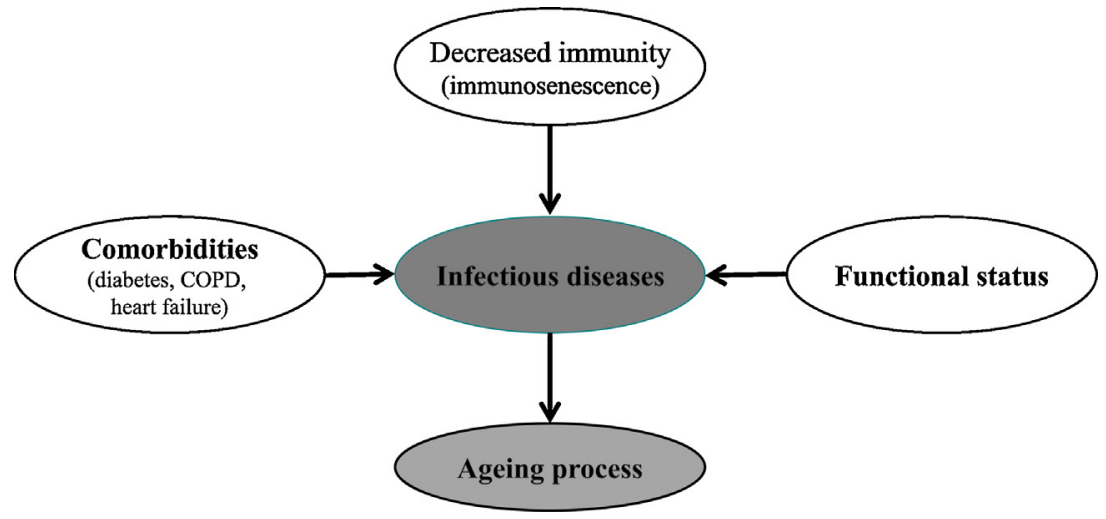

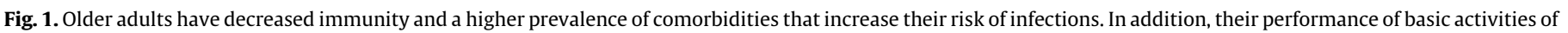
daily living prior to infection is a major determinant of survival after infection [3].

risk for infectious diseases in the elderly and the presence of underlying chronic diseases increase the risk of complications (Fig. 1) [3-5]. Recent research in geroscience is beginning to provide insights into how fundamental biologic processes of aging, such as inflammation, oxidative stress, tissue senescence including the immune system, and dysregulation of a variety of homeostatic mechanisms, could be delayed to extend 'healthspan', i.e. the healthy period of life and delay the development of chronic diseases and disability [6].

Infectious diseases in seniors often accelerate the decline in their functional status. This can be measured by the decline in basic and instrumental activities of daily living (BADL and IADL). BADL include personal care and hygiene, mobility and being able to get in and out of bed or up from a chair or sofa, toileting, bathing and feeding. IADL include cleaning and laundering, cooking and preparing food, shopping, gardening, driving or using public transport, managing medications and being able to handle finances. Many causes of catastrophic disability, defined as loss of independence for $\geq 3$ BADL, are preventable. For example, pneumonia and influenza infections, which are ranked 3rd among these causes can be prevented by vaccination [7-9]. Among those who experience catastrophic disability, $72 \%$ have been hospitalised; $33 \%$ of seniors are more disabled at hospital discharge compared with their pre-illness baseline and half of them will never recover their previous level of independence [10]. Moreover, the one-year mortality rate in seniors discharged with new or additional BADL disabilities was reported to be $41.3 \%$. Failure to recover was predicted independently by age, cardiovascular disease, dementia, cancer, low albumin and higher number of dependencies in IADLs [11]. A clinical prediction rule developed for assessing the risk of serious influenza-associated complications showed that while age was important (i.e. 58 points for those $\geq 90$ vs. 0 for those $<70$ ), other factors also contribute, such as $\geq 1$ outpatient visit/month (33 points) or previous hospitalisation for influenza or pneumonia (63 points) [12]. Vaccination against seasonal influenza has also been shown to protect against pneumonia, complications and even death, and is one means of preventing hospitalization [13-15]. Therefore, one effective means of preventing this decline is to prevent infectious diseases.

The frailty profile is partly explained by an imbalance between inflammatory and anti-inflammatory processes, which leads to a low-grade chronic pro-inflammatory state termed inflammaging [16]. Inflammatory mediators are important in resistance to infectious diseases during life, but with age they are not efficiently neutralised and are constantly present, leading to inflammaging and unsuccessful ageing. These chronic inflammatory processes increase susceptibility to chronic diseases and infectious diseases. The production of anti-inflammatory mediators in response to this chronic inflammation has been associated with more successful ageing. Current efforts to increase health span centre on slowing the fundamental biological processes of aging such as inflammation/oxidative stress, increased senescence, mitochondrial dysfunction, impaired proteostasis and reduced stress resistance [6].

Persistent infection with cytomegalovirus (CMV), which belongs to the herpes family of viruses, is very common. The infection can be spread by organ transplant, respiratory droplets, saliva, sexual contact and urine, and most people are infected by mid-life. Although most people will come into contact with CMV in their lifetime, healthy people generally do not have symptoms although the virus remains in a persistent state in multiple sites in the body. CMV seropositivity has been reported to increase with age and persistent $\mathrm{CMV}$ infection causes $\mathrm{CD} 8+\mathrm{T}$ cells to become permanently differentiated, with poor proliferative response, the senescent phenotype, which contributes to inflammaging [17].

\subsection{Vaccine-preventable infectious diseases that contribute to catastrophic disability in seniors}

Many infectious diseases, such as influenza and pneumonia, show J-curves for incidence and mortality, with younger and older individuals having a higher burden of disease and mortality. In contrast, the curve for immunity is a reverse J-curve, increasing from a young age up to a peak at about 50 years, and then declining. The decline is not homogeneous; some seniors retain good natural immunity and have good responses to vaccination, while others are more susceptible to infection (as discussed above) and have lower responses to vaccination. In addition to pneumonia and influenza, herpes zoster (HZ), another vaccine-preventable disease, can contribute to functional decline and loss of autonomy [18-20]. The higher disease burden and the lower immunity contribute to the higher risk for catastrophic disability.

Primary infection with varicella zoster virus (VZV) causes varicella and then the virus remains latent in the sensory ganglia [21]. HZ is due to reactivation of the latent VZV and, although the exact mechanism of reactivation is not well known, declining immunity with age (immunosenescence) has been reported to be the main risk factor [21]. The complications of $\mathrm{HZ}$ can be neurological, ophthalmic, dermatological and visceral, but the most important, both in terms of incidence and severity is postherpetic neuralgia (PHN) [21]. HZ occurs more frequently in older individuals, with about $2 / 3$ rd of cases in those aged $\geq 50$ years and about $2 / 3$ rd of PHN in those aged $\geq 70$ years $[18,19,22-25]$.

Even when analgesics and antiviral treatment are initiated soon after onset, chronic PHN can occur. For example, in a French study of $\mathrm{HZ}$ in general practice (ARIZONA), $80 \%$ of the patients received treatment but $10 \%$ had PHN at 1 year $[18,26]$. A specific tool, the 


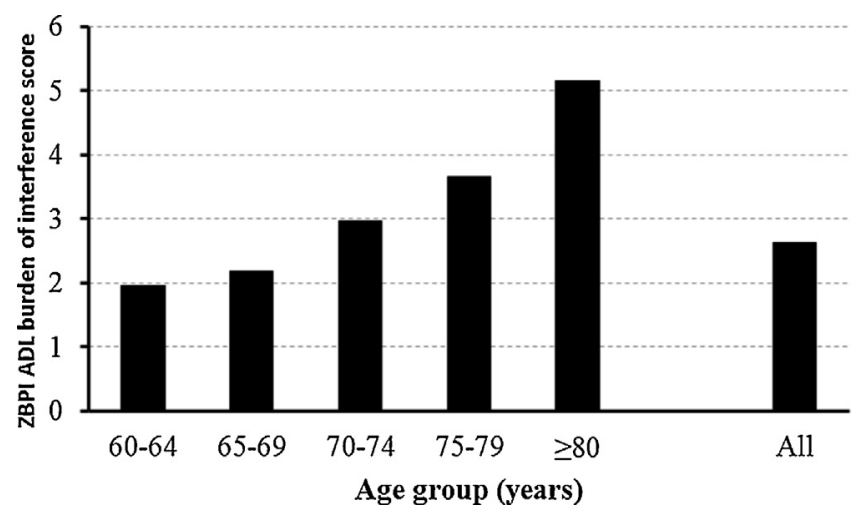

Fig. 2. Zoster Brief Pain Inventory (ZBPI) score as a function of age in the placebo group of a randomised clinical trial assessing herpes zoster vaccine vs. placebo $[20,27]$.

Zoster Brief Pain Inventory (ZBPI) has been developed to measure the impact of $\mathrm{HZ} / \mathrm{PHN}$-related pain and discomfort on seven general activities: work, sleep, walking, life enjoyment, mood, relations with others and general activity $[20,27,28]$. The results in the placebo group of a zoster vaccine clinical trial showed that the impact on ADL increased with age, and the impact continues after resolution of pain [20,29] (Fig. 2).

\section{Strategies for improving vaccination effectiveness in the elderly}

Although vaccines are available, there are some concerns about their protective potential in elders. Declining immune function in older individuals can reduce their ability to mount an effective immune response when vaccinated. As was mentioned previously, immune responsiveness increases from a young age up to peak at about 50 years, and then declines. One approach being explored involves modifying immune function to improve immune response, but this is only experimental [30]. Another approach is to

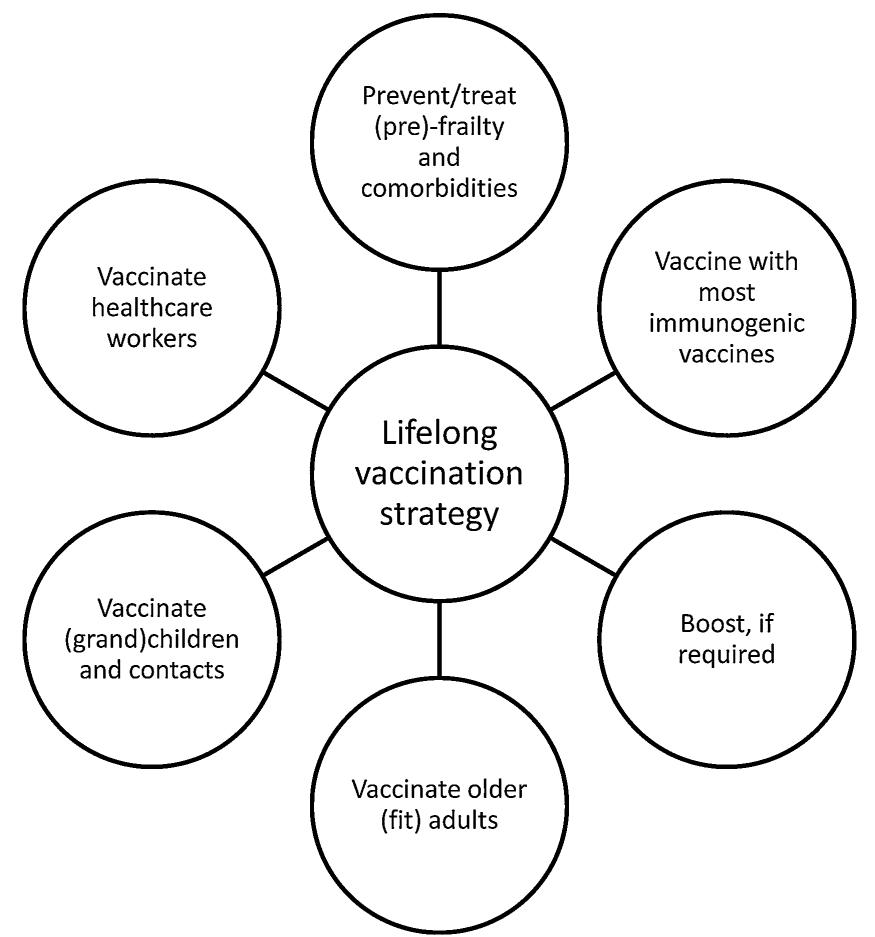

Fig. 3. Multifactorial approach to vaccination in older adults: lifelong vaccination strategy. modify the vaccine itself or its mode of administration to enhance the immune response. This approach has been used for influenza vaccine, for example, by increasing the vaccine dose, adding an adjuvant or administering via an intradermal route [31]. Another strategy would be to vaccinate adults before immunosenescence is too advanced. This requires knowing the duration of protection in this population and if boosting is needed, which is not known for pneumococcal and $\mathrm{HZ}$ vaccines at present.

Another problem concerns acceptance of adult vaccination and its impact on vaccine uptake in elderly populations, which is often low. Childhood vaccination, unlike vaccination in younger and older adults, is considered to be a beneficial intervention. Evidence suggests that prevention of $\mathrm{HZ}$ can prevent functional decline and maintain quality of life in seniors and thus contribute to successful ageing. This is likely to be true for influenza and pneumococcal pneumonia that can be associated with serious complications and lead to hospitalization. Their effective prevention would prevent functional decline and improve the health span of older adults $[18,20,27,28,32]$.

The most efficacious vaccine can only be effective if it is administered. Since the uptake rates for the elderly are variable and are often low, we need to identify efficient strategies to improve vaccine uptake and effectiveness. Vaccination strategies can be age-based, risk-based or a mix and each has its strengths and weaknesses.

The risk for infectious diseases increases as immune function declines, so we need to identify an optimal age when the immune system can respond effectively to vaccines. However, people with the same chronological age do not necessarily have the same biological age and their immune response will vary. Many vaccines for seniors are recommended for those aged $\geq 65$ years, when the immune system is already less reactive in many individuals, whereas if they were recommended for those aged $\geq 50$ years old, more individuals will be able to mount a better immune response [33]. For example, most countries recommend seasonal influenza vaccination for those aged $\geq 65$ years, but some also recommend this for healthy individuals aged 50-65, e.g. Belgium [34]. Another strategy could be lifelong vaccination, with regular boosters, to keep antibodies above protective levels, as is generally recommended for tetanus and diphtheria. More recently, recommendations for seasonal influenza vaccination in the US have been extended to all individuals aged $\geq 6$ months [35]. Extending the recommendations to younger individuals, and particularly to a lifelong vaccination recommendation, will, naturally, have economic repercussions. Starting vaccination earlier in life means that more people will need to be vaccinated and for longer. However, these additional costs need to be balanced against vaccination benefits and risk reductions. Some countries use risk-based strategies to define the vaccination target population, but many elderly people who have underlying comorbidities are unaware that they have risk factors for infectious diseases. For influenza and pneumonia many countries have a mix of age- and risk-based strategies, so that those who are at risk because of their age (young children and older adults) are also included in the strategy as well as those of any age with recognised risk factors.

Another strategy that has been used involves taking advantage of the indirect or herd protection afforded by some vaccines. For example, vaccinating children, who generally have better uptake rates, can provide protection for nontargeted age groups. For example, in Japan, influenza vaccination was recommended for children from 1962 to 1994; this was shown to reduce excess mortality from pneumonia and influenza in the elderly; after the programme was abandoned an increase of excess pneumonia and influenza mortality was observed [36]. Other studies in the US have shown that seasonal influenza vaccination for children reduced medically-attended acute respiratory diseases in adults aged 
$\geq 35$ years and pneumonia and influenza hospitalization rates in those age $\geq 65$ years, although vaccine uptake was low in the elderly [37-39]. Similar benefits have been reported in modelling studies in the UK and Germany [40,41]. This indirect protection was observed following the introduction of pneumococcal conjugate vaccine (PCV) for children in many countries $[42,43]$.

The elderly have frequent health contacts as they often have underlying diseases. Several observational studies and randomized clinical trials have shown that seasonal influenza vaccination of healthcare professionals in nursing homes and hospitals can reduce influenza-like-illness, and influenza in their patients [44-49].

\section{Conclusions}

Preventing infectious diseases and their complications in the elderly will contribute to maintaining their functional status and thus healthy ageing. Although efficacious vaccines are available, it is important to ensure that effective vaccination strategies are implemented and that vaccine uptake is sufficient. This includes defining an optimal age for vaccination to ensure that the resulting immune response is protective, and evaluating the advantages of lifelong strategies, like those used for tetanus and diphtheria (Fig. 3). The strategies for influenza and pneumonia vaccination could involve taking advantage of indirect protection by vaccinating children and HCPs who are in contact with their older grandparents or patients, respectively. It is likely that no one strategy will be sufficient or suitable for all settings, so a combination approach will need to be developed and adapted to individual healthcare settings/systems. Efficacious vaccines are available to prevent many diseases that affect the elderly, particularly, influenza, pneumonia and $\mathrm{HZ}$ and they will have an important role to play to achieve successful aging in our increasingly ageing populations.

\section{Ethical statement}

All authors state that they have respected the ethical guidelines provided at: https://www.elsevier.com/authors/journal-authors/ policies-and-ethics.

\section{Disclosure of interest}

JEM has received honoraria, consultancies and travel support for participation in advisory board and data safety and monitoring boards for Sanofi Pasteur, honoraria and travel support for presentation sponsored by Sanofi Pasteur MSD, and travel support for participation in publication committees for GSK.

GG, JF and JP declare that they have no competing interest.

\section{Acknowledgements}

Medical writing assistance in the preparation of this manuscript was provided by Margaret Haugh (MediCom Consult) funded by Sanofi Pasteur MSD. The manuscript is based on the authors' presentations at a symposium held during the meeting of the European Union Geriatric Medicine Society, 17-19 September 2014 in Rotterdam, The Netherlands.

\section{References}

[1] Ward BW, Schiller JS. Prevalence of multiple chronic conditions among US adults: estimates from the National Health Interview Survey, 2010. Prev Chronic Dis 2013;10:E65.

[2] Han L, Allore H, Murphy T, Gill T, Peduzzi P, Lin H. Dynamics of functional aging based on latent-class trajectories of activities of daily living. Ann Epidemiol 2013;23:87-92.
[3] High KP, Bradley S, Loeb M, Palmer R, Quagliarello V, Yoshikawa T. A new paradigm for clinical investigation of infectious syndromes in older adults: assessment of functional status as a risk factor and outcome measure. Clin Infect Dis 2005;40:114-22.

[4] Maijó M, Clements SJ, Ivory K, Nicoletti C, Carding SR. Nutrition, diet and immunosenescence. Mech Ageing Dev 2014;136-7:116-28.

[5] Ning Mak T, Caldeira S:. The role of nutrition in active and healthy ageing. Luxembourg: Joint Research Centre of the European Commission; 2014.

[6] Seals DR, Justice JN, LaRocca TJ. Physiological geroscience: targeting function to increase healthspan and achieve optimal longevity. J Physiolol 2015. http:// dx.doi.org/10.1113/jphysiol.2014.282665.

[7] Barker WH, Borisute H, Cox C. A study of the impact of influenza on the functional status of frail older people. Arch Intern Med 1998;158:645-50.

[8] Falsey AR, Hennessey PA, Formica MA, Cox C, Walsh EE. Respiratory syncytial virus infection in elderly and high-risk adults. N Engl J Med 2005;352:1749-59.

[9] Ferrucci L, Guralnik JM, Pahor M, Corti MC, Havlik RJ. Hospital diagnoses. Medicare charges, and nursing home admissions in the year when older persons become severely disabled. JAMA 1997;277:728-34.

[10] Covinsky KE, Palmer RM, Fortinsky RH, Counsell SR, Stewart AL, Kresevic D, et al. Loss of independence in activities of daily living in older adults hospitalized with medical illnesses: increased vulnerability with age. J Am Geriatr Soc 2003;51:451-8.

[11] Boyd CM, Landefeld CS, Counsell SR, Palmer RM, Fortinsky RH, Kresevic D, et al. Recovery of activities of daily living in older adults after hospitalization for acute medical illness. J Am Geriatr Soc 2008;56:2171-9.

[12] Hak E, Wei F, Nordin J, Mullooly J, Poblete S, Nichol KL. Development and validation of a clinical prediction rule for hospitalization due to pneumonia or influenza or death during influenza epidemics among community-dwelling elderly persons. J Infect Dis 2004;189:450-8.

[13] Beyer WE, McElhaney J, Smith DJ, Monto AS, Nguyen-Van-Tam JS, Osterhaus AD. Cochrane re-arranged: support for policies to vaccinate elderly people against influenza. Vaccine 2013;31:6030-3.

[14] Talbot HK, Griffin MR, Chen Q, Zhu Y, Williams JV, Edwards KM. Effectiveness of seasonal vaccine in preventing confirmed influenza-associated hospitalizations in community dwelling older adults. J Infect Dis 2011;203:500-8.

[15] Talbot HK, Zhu Y, Chen Q, Williams JV, Thompson MG, Griffin MR. Effectiveness of influenza vaccine for preventing laboratory-confirmed influenza hospitalizations in adults, 2011-2012 influenza season. Clin Infect Dis 2013;56:1774-7.

[16] Franceschi C, Capri M, Monti D, Giunta S, Olivieri F, Sevini F, et al. Inflammaging and anti-inflammaging: a systemic perspective on aging and longevity emerged from studies in humans. Mech Ageing Dev 2007;128:92-105.

[17] Pawelec G. Immunosenenescence: role of cytomegalovirus. Exp Gerontol 2014;54:1-5.

[18] Bouhassira D, Chassany O, Gaillat J, Hanslik T, Launay O, Mann C, et al. Patient perspective on herpes zoster and its complications: an observational prospective study in patients aged over 50 years in general practice. Pain 2012;153:342-9.

[19] Levin MJ. Immune senescence and vaccines to prevent herpes zoster in older persons. Curr Opin Immunol 2012;24:494-500.

[20] Schmader KE, Johnson GR, Saddier P, Ciarleglio M, Wang WW, Zhang JH, et al. Effect of a zoster vaccine on herpes zoster-related interference with functional status and health-related quality-of-life measures in older adults. J Am Geriatr Soc 2010;58:1634-41.

[21] Gershon AA, Gershon MD, Breuer J, Levin MJ, Oaklander AL, Griffiths PD. Advances in the understanding of the pathogenesis and epidemiology of herpes zoster. J Clin Virol 2010;48(Suppl. 1):S2-7.

[22] Dworkin RH, Schmader KE. Treatment and prevention of postherpetic neuralgia. Clin Infect Dis 2003;36:877-82.

[23] Gnann Jr JW, Whitley RJ. Clinical practice. Herpes zoster. N Engl J Med 2002;347:340-6.

[24] Opstelten W, Mauritz JW, de Wit NJ, van Wijck AJ, Stalman WA, van Essen GA Herpes zoster and postherpetic neuralgia: incidence and risk indicators using a general practice research database. Fam Pract 2002;19:471-5.

[25] Sentinelles: report 2012; 2015 (Accessed 7 April at websenti.u707.jussieu.fr sentiweb/document/2518).

[26] Johnson RW, Rice AS. Clinical practice. Postherpetic neuralgia. N Engl J Med 2014;371:1526-33

[27] Coplan PM, Schmader K, Nikas A, Chan IS, Choo P, Levin MJ, et al. Development of a measure of the burden of pain due to herpes zoster and postherpetic neuralgia for prevention trials: adaptation of the brief pain inventory. J Pain 2004;5:344-56.

[28] Schmader KE, Sloane R, Pieper C, Coplan PM, Nikas A, Saddier P, et al. The impact of acute herpes zoster pain and discomfort on functional status and quality of life in older adults. Clin J Pain 2007;23:490-6.

[29] Drolet M, Brisson M, Schmader KE, Levin MJ, Johnson R, Oxman MN, et al. The impact of herpes zoster and postherpetic neuralgia on health-related quality of life: a prospective study. CMAJ 2010;182:1731-6.

[30] Lang PO, Govind S, Bokum AT, Kenny N, Matas E, Pitts D, et al. Immune senescence and vaccination in the elderly. Curr Top Med Chem 2013;13: 2541-50.

[31] Haq K, McElhaney JE. Immunosenescence: influenza vaccination and the elderly. Curr Opin Immunol 2014;29:38-42

[32] McElhaney JE. Influenza vaccine responses in older adults. Ageing Res Rev 2011;10:379-88.

[33] Diez-Domingo J, Weinke T, Garcia de Lomas J, Meyer CU, Bertrand I, Eymin C, et al. Comparison of intramuscular and subcutaneous administration of a 
herpes zoster live-attenuated vaccine in adults aged $>=50$ years: a randomised non-inferiority clinical trial. Vaccine 2015;33:789-95.

[34] Vaccination against seasonal flu (winter 2014-2015) (9211); 2015 (Accessed 17 February 2015, at http://health.belgium.be/internet2Prd/groups/public/ @public/@shc/documents/ie2divers/19098147.pdf).

[35] Grohskopf LA, Olsen SJ, Sokolow LZ, Bresee JS, Cox NJ, Broder KR, et al. Prevention and control of seasonal influenza with vaccines: recommendations of the Advisory Committee on Immunization Practices (ACIP) - United States, 2014-15 influenza season. MMWR Morb Mortal Wkly Rep 2014;63:691-7.

[36] Reichert TA, Sugaya N, Fedson DS, Glezen WP, Simonsen L, Tashiro M. The Japanese experience with vaccinating schoolchildren against influenza. N Engl J Med 2001;344:889-96.

[37] Cohen SA, Chui KK, Naumova EN. Influenza vaccination in young children reduces influenza-associated hospitalizations in older adults, 2002-2006. J Am Geriatr Soc 2011;59:327-32.

[38] Glezen WP. Herd protection against influenza. J Clin Virol 2006;37:237-43.

[39] Piedra PA, Gaglani MJ, Kozinetz CA, Herschler G, Riggs M, Griffith M, et al. Herd immunity in adults against influenza-related illnesses with use of the trivalent-live attenuated influenza vaccine (CAIV-T) in children. Vaccine 2005;23:1540-8.

[40] Baguelin M, Flasche S, Camacho A, Demiris N, Miller E, Edmunds WJ. Assessing optimal target populations for influenza vaccination programmes: an evidence synthesis and modelling study. PLoS Med 2013;10:e1001527.

[41] Rose MA, Damm O, Greiner W, Knuf M, Wutzler P, Liese JG, et al. The epidemiological impact of childhood influenza vaccination using live-attenuated influenza vaccine (LAIV) in Germany: predictions of a simulation study. BMC Infect Dis 2014;14:40.
[42] Myint T, Madhava H, Balmer P, Christopoulou D, Attal S, Menegas D, et al. The impact of 7-valent pneumococcal conjugate vaccine on invasive pneumococcal disease: a literature review. Adv Ther 2013;30:127-51.

[43] Pebody RG, Leino T, Nohynek H, Hellenbrand W, Salmaso S, Ruutu P. Pneumococcal vaccination policy in Europe. Euro Surveill 2005;10:174-8.

[44] Ahmed F, Lindley MC, Allred N, Weinbaum CM, Grohskopf L. Effect of influenza vaccination of healthcare personnel on morbidity and mortality among patients: systematic review and grading of evidence. Clin Infect Dis 2014;58:50-7.

[45] Carman WF, Elder AG, Wallace LA, McAulay K, Walker A, Murray GD, et al. Effects of influenza vaccination of health-care workers on mortality of elderly people in long-term care: a randomised controlled trial. Lancet 2000;355: 93-7.

[46] Hayward AC, Harling R, Wetten S, Johnson AM, Munro S, Smedley J, et al. Effectiveness of an influenza vaccine programme for care home staff to prevent death, morbidity, and health service use among residents: cluster randomised controlled trial. BMJ 2006;333:1241-50.

[47] Lemaitre M, Meret T, Rothan-Tondeur M, Belmin J, Lejonc JL, Luquel L, et al. Effect of influenza vaccination of nursing home staff on mortality of residents: a cluster-randomized trial. J Am Geriatr Soc 2009;57:1580-6.

[48] Oshitani H, Saito R, Seki N, Tanabe N, Yamazaki O, Hayashi S, et al. Influenza vaccination levels and influenza-like illness in long-term-care facilities for elderly people in Niigata, Japan, during an influenza A (H3N2) epidemic. Infect Control Hosp Epidemiol 2000;21:728-30.

[49] Thomas RE, Jefferson T, Lasserson TJ. Influenza vaccination for healthcare workers who work with the elderly: systematic review. Vaccine 2010;29: 344-56. 